Pramāṇa, Vol. 23, No. 6, December 1984, pp. L815-L818. (C) Printed in India.

\title{
An Auger electron spectroscopic investigation of the electron states of copper alloys
}

\author{
P SEN, D D SARMA and C N R RAO \\ Solid State and Structural Chemistry Unit, Indian Institute of Science, \\ Bangalore 560012, India \\ MS received 28 July 1984
}

\begin{abstract}
L}_{3} \mathrm{VV}$ Auger transitions of copper alloys show a feature due to a band-like states, the shape and intensity of which depend on the composition. The energy separation between this feature and the $L_{3} M_{45} M_{45}$ peak increases progressively with $\mathrm{Cu}$ concentration.
\end{abstract}

Keywords. Auger transitions; electron states; copper alloy.

PACS Na. $71 \cdot 20 ; 79 \cdot 20$

\section{Introduction}

Unlike x-ray photoelectron spectroscopy (XPS), Auger electron spectroscopy (AES) has not been employed extensively to investigate electron states of metal alloys. AEs should be specially useful in examining perturbations of the $d$-bands of transition metal alloys and to observe features due to band-like density of $d$-states. We have investigated several alloys of copper, both crystalline and glassy, and have obtained encouraging results.

\section{Experimental}

$X$-ray photoelectron spectra and x-ray induced Auger electron spectra were recorded using an ESCA 3 Mark II spectrometer (VG Scientific Ltd., UK), fitted with a sample preparation chamber, a gas handling manifold and $\mathrm{Ar}^{+}$etching facility (Rao et al 1979). The Au $\left(4 f_{7 / 2}\right)$ signal at $83.7 \mathrm{eV}$ was used for energy calibration of the spectrometer.

$\mathrm{Cu}-\mathrm{Zr}$ metglasses were prepared by rapid quenching from the melt (Sen et al 1984). $\mathrm{Cu}-\mathrm{Al}$ and $\mathrm{Cu}-\mathrm{Mn}$ alloys were prepared by induction melting under vacuum. Electron beam melting was employed for the $\mathrm{Cu}-\mathrm{Pd}$ system and the remaining alloys were prepared in an induction furnace in argon atmosphere.

All the samples were first cleaned and polished mechanically before introduction in to the vacuum $\left(2 \times 10^{-10}\right.$ Torr $)$ of the sample preparation chamber of the spectrometer. Subsequently, the samples were cleaned by scraping them in situ with a stainless steel file. Surface compositions of samples were determined by XPS. All the studies were carried out at room temperature $(298 \mathrm{~K})$. 


\section{Results and discussion}

In figure 1 , we show the $\mathrm{L}_{3} \mathrm{VV}$ region of $\mathrm{Cu}$ in $\mathrm{Cu}$ metal and glassy $\mathrm{Cu}_{50} \mathrm{Zr}_{50}$. The $L_{3} M_{45} M_{45}$ Auger structure appearing between 912 and $923 \mathrm{eV}$, clearly shows five distinct features (marked A,B,C, D and E) similar to those noticed by earlier workers (Antonides et al 1977). These features arise from quasi-atomic two-hole excitations in the $d$-level and double ionization processes. We have decomposed these multiplets in terms of five gaussian peaks by a least-squared-error procedure after substracting the background. This analysis shows that the central intense peak (C) contributes $45 \%$ of the total intensity in $\mathrm{Cu}$ metal and $42-44 \%$ in the other alloys studied, with the exception of the two metglasses, $\mathrm{Cu}_{50} \mathrm{Zr}_{50}$ and $\mathrm{Cu}_{30} \mathrm{Zr}_{70}$, where the contribution of peak $\mathrm{C}$ is only $30-32 \%$. The intensity of $\mathrm{C}$ increases up to $48 \%$ on depositing potassium on $\mathrm{Cu}$ metal. Such yariations in the relative intensities of the component peaks suggest that the $\mathrm{L}_{3} \mathbf{M}_{45} \mathbf{M}_{45}$ transition of $\mathrm{Cu}$ in these alloys involves band-like states. Besides the $L_{3} M_{45} M_{45}$ structure, figure 1 also shows a broad feature $(F)$ between 924 and $930 \mathrm{eV}$. We assign this feature to the band part of the $\mathrm{L}_{3} \mathbf{M}_{\mathbf{4 5}} \mathrm{M}_{\mathbf{4 5}}$ spectrum. This assignment finds support from the studies of Weightman and Andrews (1979) as well as of Sawatzky (1977).

We have investigated the F peak around $927 \mathrm{eV}$, assigned to band-like density of $d$ states convoluted with itself, in several crystalline alloys of $\mathrm{Cu}$ with $\mathrm{Mn}$ and $\mathrm{Ni}$ as well as in the metglasses with $\mathrm{Zr}$ and find that its shape and intensity change from alloy to alloy (see figure 2a). In $\mathrm{Cu}-\mathrm{Zr}$ alloys, the feature becomes narrower with decreasing $\mathrm{Cu}$ concentration, suggesting an increased atomic impurity-like behaviour of $\mathrm{Cu}$ in the matrix of $\mathrm{Zr}$. These changes are likely to arise from a narrowing of the $\mathrm{Cu}(3 d)$ level due

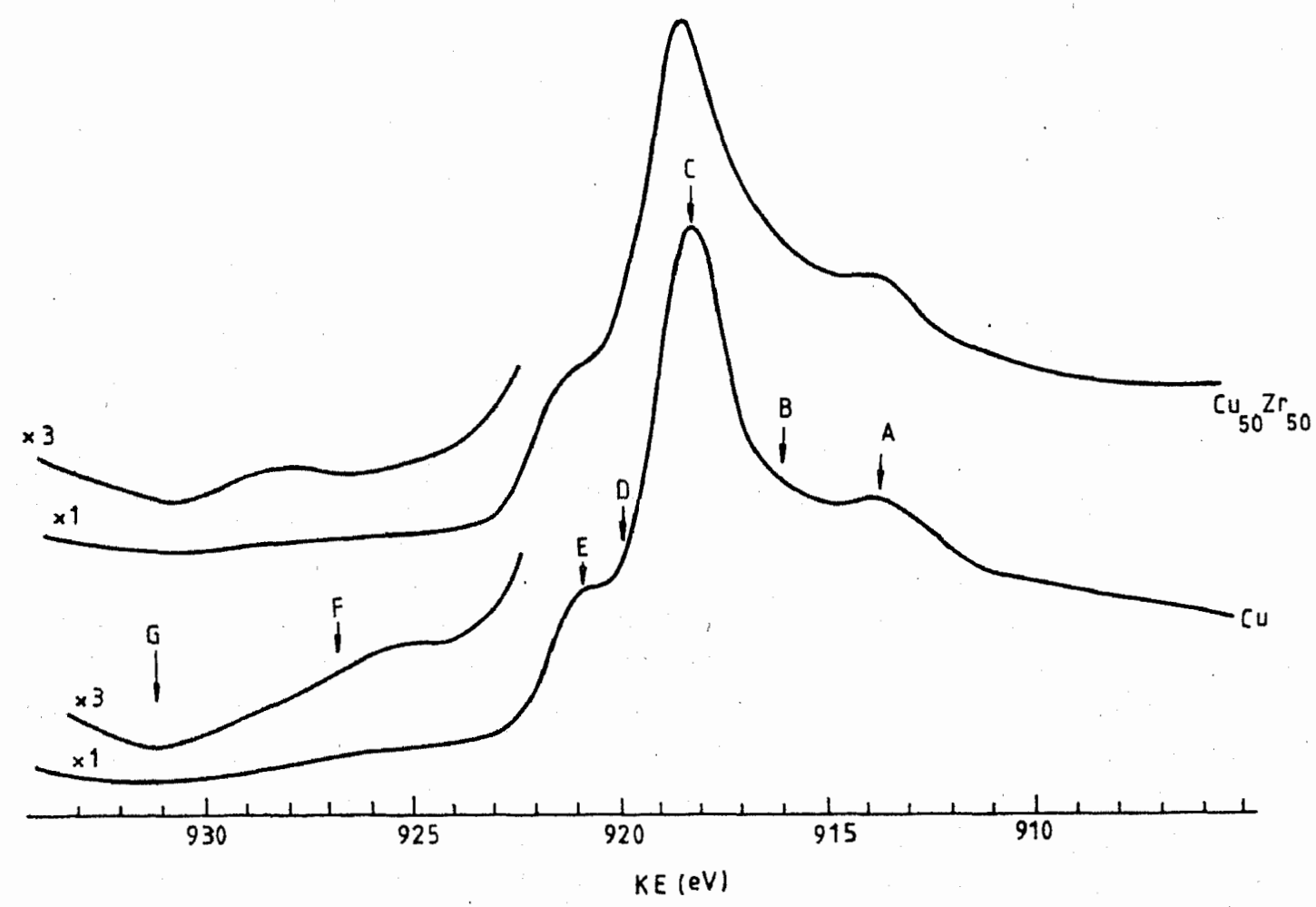

Figure 1. X-ray induced $\mathrm{L}_{3} \mathrm{VV}\left(\mathrm{L}_{3} \mathrm{M}_{45} \mathrm{M}_{45}\right)$ Auger spectra of $\mathrm{Cu}$ in $\mathrm{Cu}$ metal and $\mathrm{Cu}_{50} \mathrm{Zr}_{50}$ metglass. The high energy side of the signal has been expanded to show the band part of $\mathbf{L}_{3}$ VV transition. 
(a)

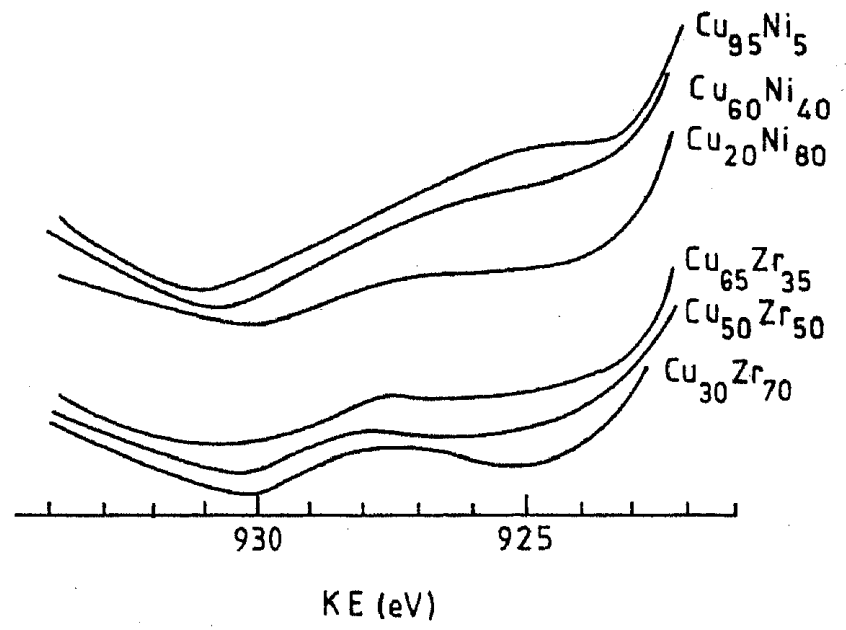

(b)

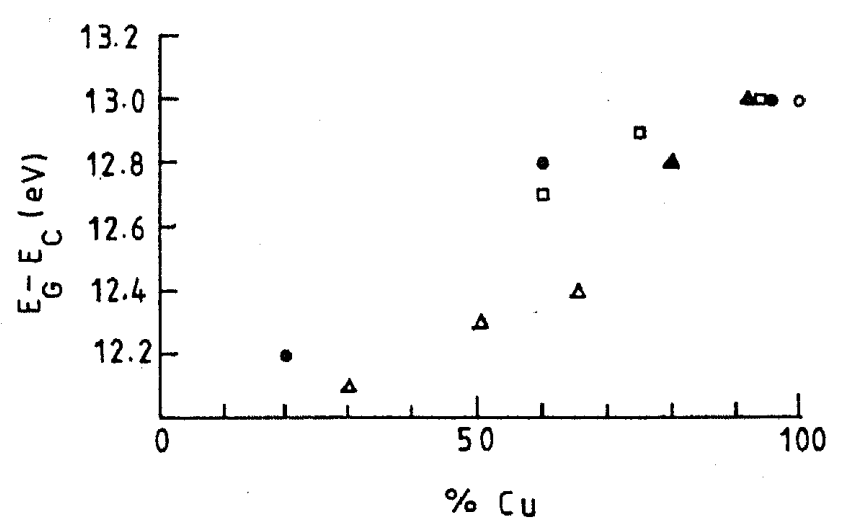

Figure 2. a) Band part of $\mathrm{Cu}\left(\mathrm{L}_{3}\right.$ VV) Auger transition in crystalline $\mathrm{Cu}-\mathrm{Ni}$ alloys and $\mathrm{Cu}-\mathrm{Zr}$ metglass. b) Plot of $E_{\mathrm{G}}-E_{\mathrm{C}}$ against atomic \% of $\mathrm{Cu}$ in $\mathrm{Cu}$ alloys: $\mathrm{Cu}$ (open circles); $\mathrm{Cu}-\mathrm{Ni}$ (full circles); $\mathrm{Cu}-\mathrm{Zr}$ (open triangles); $\mathrm{Cu}-\mathrm{Al}$ (full triangles) and $\mathrm{Cu}-\mathrm{Mn}$ (open squares).

to increase in $3 d-4 d$ overlap. In $\mathrm{Cu}-\mathrm{Ni}$ alloys however, the intensity of the feature decreases with decreasing $\mathrm{Cu}$ concentration with no evidence of $s$-band localization. We have found similar changes in $\mathrm{Cu}-\mathrm{Al}$ and $\mathrm{Cu}-\mathrm{Mn}$ alloys.

In figure 1, we also see a dip (marked G) in intensity around $931 \mathrm{eV}$ appearing between the rising parts of the band-derived $\mathrm{L}_{3} \mathrm{M}_{45} \mathrm{M}_{45}$ feature (F) and the smoothly decaying part of the $L_{2} M_{45} M_{45}$ transition. We may point out here that $G$ would have appeared at $L_{3}$ binding energy, had there been no decaying tail of the $L_{2} M_{45} M_{45}$ transition. The presence of the latter makes $G$ appear as a dip and pushes it to lower kinetic energy, the magnitude of the energy shift depending on the intensity of the band part of the $\mathrm{L}_{3} \mathrm{M}_{45} \mathrm{M}_{45}$ transition. The energy difference between $\mathrm{G}$ and the most intense peak $\mathrm{C}, E_{\mathrm{G}}-E_{\mathrm{C}}$, decreases progressively with the decreasing $\mathrm{Cu}$ concentration irrespective of the alloy systems (figure $2 \mathrm{~b}$ ). It is noteworthy that the $\mathrm{Cu}-\mathrm{Zr}$ system exhibits a more pronounced decrease in $E_{\mathrm{G}}-E_{\mathrm{C}}$ compared to other alloys. This is in accord with the fact that the $\mathrm{Cu}(3 d)$ signal in XPs shifts away from $E_{\mathrm{F}}$ when alloyed with Zr. 
In Cu-Pd alloys, we find that the $\operatorname{Pd}\left(\mathrm{M}_{45} \mathrm{~N}_{45} \mathrm{~N}_{45}\right)$ transition energy shifts to lower kinetic energy by $\sim 1.5 \mathrm{eV}$ in going from $\mathrm{Pd}$ to $\mathrm{Cu}_{92} \mathrm{Pd}_{8}$ indicating an increase in the $\mathrm{U}_{\mathrm{eff}}$ value for dilute $\mathrm{Pd}$ alloys. This observation suggests a narrowing of the $\mathrm{Pd}(4 \mathrm{~d})$ level on dilution.

\section{Acknowledgement}

The authors thank the DST, Government of India and the UGC for support.

\section{References}

Antonides E, Jance E C and Sawatzky G A 1977 Phys. Rev. B15 1669

Rao C N R, Sarma D D, Vasudevan S and Hegde M S 1979 Proc. R. Soc. A367 239

Sawatzky G A 1977 Phys. Rev. Lett. 39504

Sen P, Sarma D D, Budhani R C, Chopra T L and Rao C N R 1984 J. Phys. F14 565

Weightman P and Andrews P T 1979 J. Phys. C12 943 